\title{
Multiple Memory Processes Following Training That a Food Is Inedible in A plysia
} Dina Botzer, Silvia Markovich, and Abraham J. Sussw ein ${ }^{1}$

Department of Life Sciences

Bar-Ilan University

Ramat-Gan 52 900, Israel

\begin{abstract}
In many organisms, memory after training can be separated into a number of processes. We now report that separable memory processes are also initiated by a training procedure affecting Aplysia feeding behavior, a model system for examining the neural mechanisms underlying the regulation of a complex behavior. Four distinct memory process were identified: (1) a very short-term memory that declines within $15 \mathrm{~min}$, (2) a short-term memory that persists for 0.5-1.0 hr, (3) an intermediate-term memory, observed $4 \mathrm{hr}$ after training, and (4) a long-term memory that is seen only after a 12- to 24-hr delay. The four memory processes can be distinguished by the different training procedures that are required to elicit them. A single 5-min training session is sufficient to elicit the very short-term memory. However, a longer training session that continues until the animal stops responding to food is needed to elicit short-term memory. Intermediate-term memory is observed only after a spaced training procedure (three 5-min training sessions separated by $30-\mathrm{min}$ intervals). A single 5-min training session that does not cause either short-term or intermediate-term memory is sufficient to induce long-term memory, indicating that short- and long-term memory are independent, parallel processes. Short- and long-term memory can also be separated by the effects of a post-training experience. Long-term, but not short-term, memory can be attenuated by cooling animals immediately after training.
\end{abstract}

${ }^{1}$ Corresponding author.
Cooling before the training does not affect either the training or the subsequent shortor long-term memory.

\section{Introduction}

Memory following learning is not a unitary process in either vertebrates or invertebrates (Dudai 1989). Learning initiates a variety of different, partially independent memory processes that can be characterized by differences in their time course, anatomical localization, and sensitivity to posttraining events, such as physical stress or pharmacological agents (Squire 1987). In humans, active or working memory refers to memory needed to perform the current, ongoing task. This process arises from the sustained activity of neurons that are responsible for coding the memory (GoldmanRakic 1995). Short-term memory is shown from a period of a few minutes to a few hours after learning and generally arises from covalent modifications of pre-existing proteins, which leads to changes in the physiology and biochemistry of the neurons storing the memory (Kandel and Schw artz 1982; Dudai 1989). Long-term memory becomes evident somewhat later and can be maintained for days, weeks, or a lifetime (Squire 1987; Dudai 1989). Inhibition of protein synthesis, as well as heat, cold, or electroconvulsive shock, can disrupt the formation of long-term memory before it is consolidated. How ever, once the long-term memory is fully formed, it is generally resistant to these procedures (Squire 1987; Dudai 1989). Although different forms of memory can be shown to exist by a variety of experimental procedures, in the $a b$ sence of intervention the various memory processes usually succeed one another gradually and often overlap (DeZazzo and Tully 1995), producing the illusion of a single, continuous process.

Insight into the cellular and molecular processes underlying memory has come from a num-

LEARN IN G \& MEM ORY 5:204-219 @ 1998 by Cold Spring Harbor Laboratory Press ISSN 1072-0502/98 \$5.00

$$
\begin{array}{lllllllllllllll}
L & E & A & R & N & I & N & G & \underset{204}{\mathbf{X}} & M & E & M & O & R & Y
\end{array}
$$


ber of preparations. For facilitation of Aplysia withdrawal reflexes (Carew and Sahley 1986; Byrne 1987), short- and long-term memory are partially mediated by the activation of a common secondmessenger system, the cyclic AMP (cAMP) cascade. Modulation of $\mathrm{K}^{+}$channels is responsible for many of the short-term effects (Byrne and Kandel 1996), whereas long-term effects are initiated by CAMPdependent transcription (Dash et al. 1990; Bacskai et al. 1993). Short-term memory is maintained for $<30$ min, whereas long-term memory becomes evident only after a delay of $>12 \mathrm{hr}$ (Emptage and Carew 1993; Ghirardi et al. 1995; Mauelshagen et al. 1996). Between short- and long-term memory, a separable intermediate term memory can be identified (Ghirardi et al. 1995; Mauelshagen et al. 1996), which is dependent on translation, but not transcription (Ghirardi et al. 1995). In this system, short- and long-term memory are independent, parallel processes, because long-term memory can be attained without the previous expression of shortterm memory (Emptage and Carew 1993; Mauelshagen et al. 1996). In Drosophila, separable short-, intermediate-, and long-term memory processes have also been identified that are dependent on the CAMP cascade (DeZazzo and Tully 1995). However, in this system, mutants that disrupt earlier stages of memory also disrupt later stages (Tully et al. 1994), indicating a dependency of the later memory stages on the preceding short- and intermediate-term memory processes. Some of the molecular events that are associated with shortand long-term neuronal plasticity underlying memory in mammals seem to be similar to those that occur in Aplysia and Drosophila (Bourtchuladze et al. 1994; Huang et al. 1994; Abel et al. 1997; Guzowski and McGaugh 1997).

In this paper we examine the relationships between different stages of memory caused by a learning paradigm that affects Aplysia feeding behavior. In this paradigm, Aplysia modify their feeding behavior as a consequence of their success or failure to swallow a particular food stimulus (Susswein et al. 1986). This training paradigm is of particular interest, because a neural analog similar to aspects of the behavioral paradigm has recently been developed (Nargeot et al. 1997). In addition, the training paradigm is likely to affect well-characterized, identified neurons that control feeding (Weiss et al. 1978; Susswein and Byrne 1988; Plummer and Kirk 1990; Teyke et al. 1990; Rosen et al. 1991; Hurwitz and Susswein 1996; Perrins and Weiss 1996; Hurwitz et al. 1997). Following train- ing, long-term memory has been demonstrated from a period of $24 \mathrm{hr}$ until 3 w eeks (Schw arz et al. 1991). How ever, no systematic studies have examined short-term memory or the processes that govern the conversion of short-term to long-term memory. This paper examines the properties of memory during the first $24 \mathrm{hr}$ after training that affects Aplysia feeding, and compares the memory processes during this period with those observed after training procedures that affect Aplysia synapses, as well as after training in other animals.

Aplysia feeding begins with appetitive movements, by which animals locate food. Food touching the lips initiates biting, which causes food to enter the mouth. Swallowing is triggered by food within the mouth. Food or nonfood objects in the mouth can also trigger rejection (Kupfermann 1974). In both ingestion (biting and swallowing) and rejection, the toothed radula first moves forward (protraction) and then backward (retraction). Protraction and retraction are coupled with opening and closing of the radula halves (Morton and Chiel 1993). Switching between ingestion and rejection arises by changing the relative amplitude of the protraction and retraction and by changing the coupling between the protraction-retraction sequence and the accompanying radula opening and closing (Morton and Chiel 1993). In ingestion, the retraction moves food into the mouth or gut. The radula halves are open during a weak protraction and are closed during a powerful retraction. During rejection the protraction phase moves food or nonfood objects out. The radula halves are closed during a powerful protraction, and a weak retraction occurs with the radula halves open. A common central pattern generator gives rise to both ingestion and rejection movements (Hurwitz et al. 1996; Kabotyanski et al. 1998). Neurons that modulate the patterns, thereby playing a role in switching between ingestion and egestion movements, have recently been characterized (Hurwitz et al. 1997; Kabotyanski et al. 1998; R. Nargeot, D.A. Baxter, and J.H. Byrne, unpubl.).

In the training procedure that affects feeding, food is made inedible by w rapping it in plastic net (Susswein et al. 1986). When netted food touches the lips, animals taste the food through holes in the net. Animals bite, and food enters the mouth and there elicits swallows that fail to convey the tough food to the gut. The food eventually is rejected. Food continues stimulating the lips and elicits bites, which again lead to failed swallows. As training proceeds, the response of the animal to the

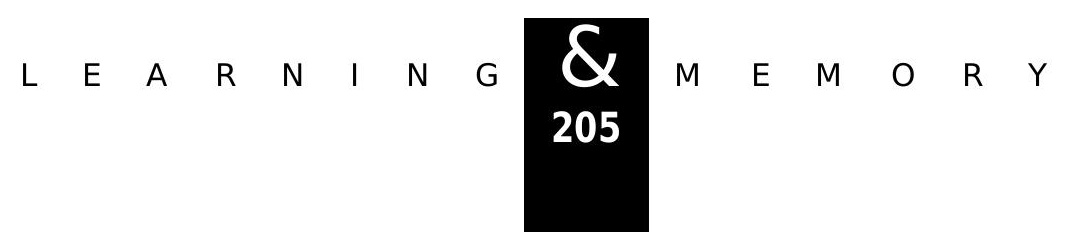


food gradually changes. Food stays within the mouth for progressively shorter periods, eliciting few er sw allows and more rejections. Animals eventually stop responding to the food (Sussw ein et al. 1986). Memory after training is show $n$ by savings in the time needed to stop responding to food when animals are retrained, as well as by changes in the motor pattern elicited by food, such as a relative increase in the likelihood to reject food rather than to ingest it. Memory is specific to the taste and texture of the food used in the training (Sussw ein et al. 1986; Schwarz et al. 1988, 1991). The memory arises as a result of an associative learning process, in which animals pair sensory stimuli elicited by food with an internal negative reinforcing stimulus arising from their failure to swallow the food during the training (Sussw ein et al. 1986).

We now report that different training procedures, as w ell as cooling immediately after training, reveal four separable memory processes: very short $(<15 \mathrm{~min})$, short $(<1 \mathrm{hr})$, intermediate $(\sim 4$ $\mathrm{hr}$ ), and long term ( $>12 \mathrm{hr}$ ). Moreover, long-term memory can be expressed in animals that have not previously expressed short-term or intermediateterm memory, indicating that these are independent, parallel memory processes.

\section{Materials and Methods}

\section{ANIMALS}

Experiments were performed on Aplysia fasciata and on Aplysia californica. A fasciata weighed 80-160 grams and were collected along the Mediterranean coast of Israel. A. californica weighed 100-150 grams and were purchased from Marine Specimens Unlimited (Pacific Palisades, CA). The species used in each experiment is noted. Animals were stored five to six to a cage in plastic mesh cages that were immersed in 1300-liter tanks of aerated, filtered Mediterranean seaw ater at $18^{\circ} \mathrm{C}$ with lighting at 12:12 hr light-dark. The animals were fed one to two times weekly with Ulva lactuca, which was gathered along with A. fasciata and was stored frozen.

One w eek before an experiment, animals w ere separated from one another. They were thereafter kept in individual cages and were deprived food. Twenty-four hours before an experiment they were transferred to 10-liter experimental aquaria that were maintained at $19-20^{\circ} \mathrm{C}$. Because in $\mathrm{A}$. fasciata the presence of a conspecific in the environment is needed for animals to learn that a food is inedible (Schwarz and Sussw ein 1992), a second Aplysia was alw ays transferred to the experimental aquarium along with the experimental animal. The second animal was maintained behind a partition that was not a barrier to the flow of seawater but that prevented contact between the animals. Because A. californica are diurnally active (Kupfermann 1968) and A. fasciata are nocturnal animals (Ziv et al. 1991), experiments on A. californica were performed during the light portion of the day, whereas those on A. fasciata were done during the dark portion, as described previously (Susswein et al. 1986).

\section{TRAINING PROCEDURE}

As in previous studies (Schwarz and Susswein 1986; Susswein et al. 1986; Schwarz et al. 1988, 1991), training begins by touching a small piece of Ulva wrapped in plastic net to the rhinophores of animals. Aplysia respond to this stimulus by lifting the head and centering food on the lips. Food on the lips initiates a biting response, which leads to entry of food into the buccal cavity. Food in the buccal cavity leads to swallowing responses. However, because netted food physically cannot be swallowed, it becomes lodged in the buccal cavity, where it produces repetitive failed swallowing responses. Food eventually leaves the buccal cavity. The netted food continues to stimulate the lips, producing further biting responses, which again leads to failed swallows. As training proceeds, many responses fail to lead to entry of food into the buccal cavity. When food enters the buccal cavity, it stays within the cavity for progressively shorter periods, eliciting fewer attempted swallowing responses. Finally, animals stop responding to the netted food. The criterion for cessation of responsiveness was 3 min without food entering the mouth. This criterion is somew hat different from that in previous experiments, in which training was stopped when there was one response of any type in $3 \mathrm{~min}$, and therefore the time to stop responding in the present experiments was somewhat shorter. In all experiments, biting responses and entry and exit of food into and from the buccal cavity were observed visually, and occurrences were noted by pressing the appropriate button of a three-button mouse connected to a computer. A computer program noted the time that the mouse button was touched. In addition, swallowing re-

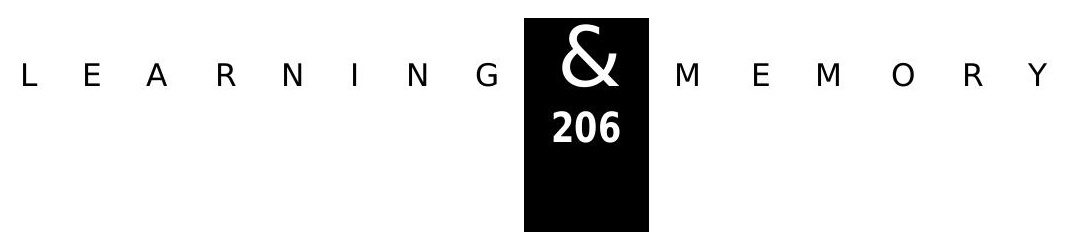


sponses that were felt by the experimenter as an inward pull on the netted food were also noted. Two parameters of learning and memory were used: (1) time taken to stop responding to food and (2) time spent by food in the buccal cavity (Susswein et al. 1986).

\section{COOLING}

Animals were removed from the water, placed in a tray without water, and then transported within $15-30 \mathrm{sec}$ to a freezer $\left(-20^{\circ} \mathrm{C}\right)$ for $15 \mathrm{~min}$.

\section{STATISTICS}

In many experiments, the presence of memory was revealed using a paired t-test $(\alpha=0.5)$ that revealed a significant reduction of performance during a test, with respect to that seen in the same animals during an initial training. In two experiments, the effect of a 5-min training on retention that $w$ as measured at a variety of later periods was compared, using t-tests $(\alpha=0.05)$. A one-way ANOVA and subsequent multiple comparison tests $(\alpha=0.05)$ were used to compare the effects of three different training procedures (one or multiple 5-min training sessions or a single massed training session) on retention after $4 \mathrm{hr}$. Finally, a t-test ( $\alpha=0.5$ ) was used to compare the effects of cooling before and after training. Subsequent ANOVAs w ere used to determined whether the savings after cooling were similar or different from the values measured in previous experiments on uncooled animals.

\section{Results}

\section{LONG-AND SHORT-TERM MEMORY ARE SEPARABLE}

Previous experiments (Schwarz et al. 1988, 1991) showed that a single training session until an animal stops responding to inedible netted food leads a decrease in responsiveness immediately after the training, as well as a decrement in responsiveness after $24 \mathrm{hr}$. How ever, no data were available regarding memory during intermediate intervals following training.

A series of experiments tested memory at intervals from $5 \mathrm{~min}$ to $24 \mathrm{hr}$ after training. In these experiments, A. fasciata were trained until they stopped responding to inedible food, and the memory following training was then examined by testing them with a procedure identical to the original training. As in previous studies (Sussw ein et al. 1986; Schwarz et al. 1991), memory was measured by two criteria: (1) a decrease in the time needed to stop responding to food in the test session, with respect to that seen when the same animals were naive and (2) a decrease in responsiveness to food at the start of the test session, with respect to that seen in the same animals at the start of training, when they were naive animals. Responsiveness to the food was measured by noting the time that food spent in the mouth over the first 5 min of a training or testing session. Tests of memory were performed either $5 \mathrm{~min}, 30 \mathrm{~min}, 1$ hr, $4 \mathrm{hr}, 12 \mathrm{hr}$, or $24 \mathrm{hr}$ after training (Fig. 1). The experiment used a blind procedure: During the second (test) sessions, naive animals that had not been trained previously were also examined, and the experimenter was unaware of the identity of the animals.
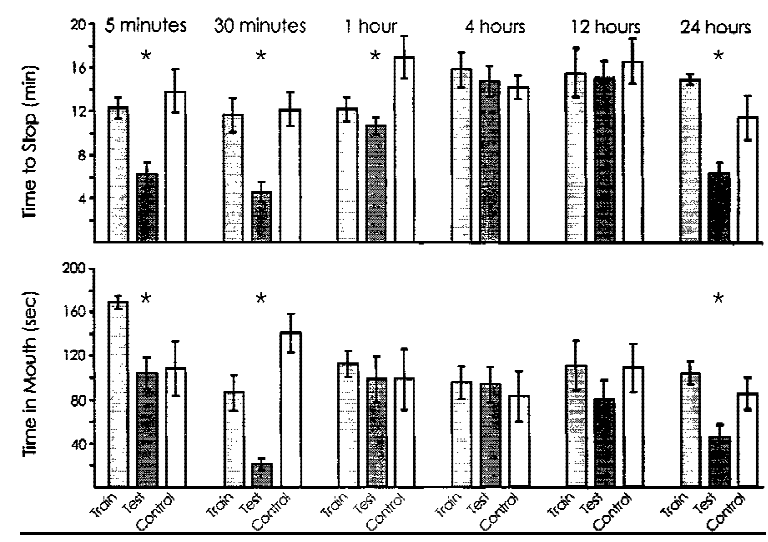

Figure 1: Memory after different time periods. Animals were trained until they stopped responding to food and then were tested at various intervals following the end of the training. For 5-min testing, $n=5$; for 30-min testing, $n=9$; for 1-hr testing, $n=12$, for 4-hr testing, $n=13$, for 12-hr testing, $n=6$; for 24-hr testing, $n=6$. Two parameters were measured during the training and during the subsequent test: (1) the time to stop responding to the food (top) and (2) the time that food was in the mouth during the first 5 min (bottom). All tests were run along with blind controls (for 5 -min test, $n=5$; for 30-min test, $n=5$; for 1-hr test, $n=7$; for 4-hr test, $n=4$; for 12 -hr test, $n=6$; for 24 -hr test, $n=6$ ). The figure shows the means and S.E.S of the values during the initial training, during the subsequent test, and for the controls run along with the test. Asterisks (*) mark time intervals in which there was a significant difference between the values observed between the original training and the subsequent test (e.g., memory was shown). 
Botzer et al.

Significant memory was observed $5 \mathrm{~min}$ and 30 min after the animals were trained, as well as 1 $\mathrm{hr}$ and $24 \mathrm{hr}$ after training, as measured by a decrease in the time needed to stop responding to food [for $5 \mathrm{~min}$ : $\mathrm{P}=0.002, \mathrm{t}(4)=5.69$; for $30 \mathrm{~min}$ : $\mathrm{P}<0.001, \quad \mathrm{t}(8)=5.46$; for $1 \mathrm{hr}: \mathrm{P}=0.05$, $\mathrm{t}(11)=1.85$; for $24 \mathrm{hr}: \mathrm{P}<0.001, \mathrm{t}(5)=6.28]$. In contrast, no significant memory was observed $4 \mathrm{hr}$ or $12 \mathrm{hr}$ after the training, as measured by a decrease in the time needed to stop responding [for $4 \mathrm{hr}: \mathrm{P}=0.25, \mathrm{t}(12)=1.19$; for $12 \mathrm{hr}: \mathrm{P}=0.65$, $t(5)=0.47]$. Decreases in the time that food spent in the mouth during the first 5 min were seen 5 $\mathrm{min}, 30 \mathrm{~min}$, and $24 \mathrm{hr}$ after training [for $5 \mathrm{~min}$ : $\mathrm{P}=0.006, \mathrm{t}(4)=4.40$; for $30 \mathrm{~min}: \mathrm{P}=0.001$, $\mathrm{t}(8)=4.21$; for $24 \mathrm{hr}: \mathrm{P}=0.02, \mathrm{t}(5)=3.00]$, but no significant decreases in the time that food was in the mouth during the first 5 min were seen 1, 4, or $12 \mathrm{hr}$ after the initial training [for $1 \mathrm{hr}: \mathrm{P}=0.17$, $t(11)=0.98$; for $4 \mathrm{hr}: \mathrm{P}=0.43, \mathrm{t}(12)=0.19$; for 12 hr: $\mathrm{P}=0.06, \mathrm{t}(5)=1.87$; all of the above are onetailed paired t-tests]. These findings indicate that a single training session until animals stop responding causes separable short-term and long-term memory processes. Short-term memory persists for $1 \mathrm{hr}$ or less, whereas long-term memory begins to appear only after $12 \mathrm{hr}$. No memory is seen for an intermediate period of $\sim 1-12 \mathrm{hr}$ after training (Fig. 2).

In previous experiments that examined longterm memory, training and testing were performed at similar hours of the day, and so the possible influence of circadian variables on the animals' responses was avoided. How ever, the design of the present experiment prevented us from training and testing animals at the same time of day. It is therefore possible that the seeming lack of memory from 1 to $12 \mathrm{hr}$ after training stems from an elevation of the animals' responsiveness as a result of factors related to a circadian oscillator. To test this possibility, we examined whether there were systematic changes in the values observed in the blind controls, which were tested at the same time of day as were the memory tests in the experimental animals. There were no significant differences between the six control groups $(n=33$ animals in all) in either the time needed to stop responding $[\mathrm{P}=0.211, \mathrm{~F}(5,27)=1.54]$, or in the time that food was in the mouth during the first 5 $\min [\mathrm{P}=0.58, \mathrm{~F}(5,27)=0.76$; one-way ANOVAs]. Values in the control animals were similar to those in the first training session of the experimental animals ( $\mathrm{n}=51$ animals), when they were naive [for

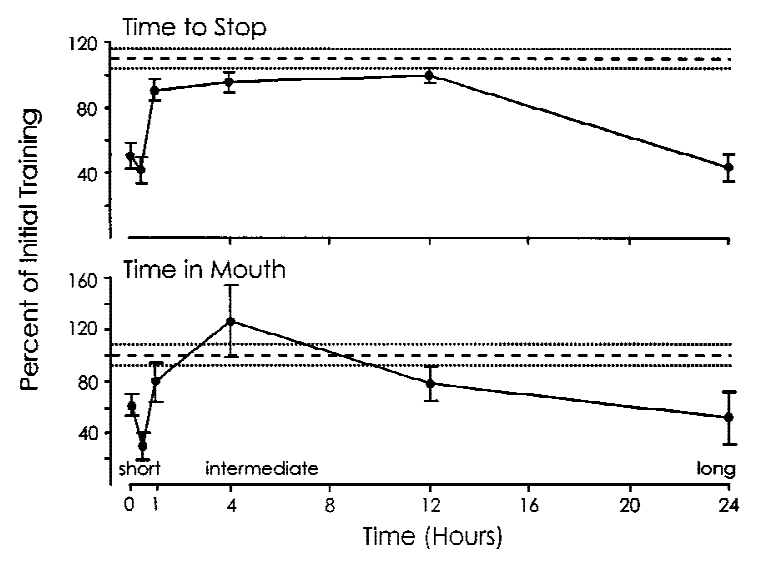

Figure 2: Time course of memory. D ata from Fig. 2 for all values measured during a test were normalized and expressed a percentage of the value in the same animal during the initial training, to illustrate the time course of short- and long-term memory more clearly. The time periods during which short-, intermediate- (Fig. 5, see below), and long-term memories are expressed are noted. S.E.S are shown. All tests were run along with blind controls. Also shown are the mean and S.E.S of the combined value for all of the controls (broken lines), expressed as a percentage of the mean value observed in all of the animals during the initial training.

the first training session, the mean time to stop was $13.62 \pm 4.57$ (S.D.) min, and the mean time spent in the mouth during the first 5 min was $104 \pm 52.67$ (S.D.) sec; for the control animals, the mean time to stop was $14.42 \pm 4.70$ (S.D.) min, and the mean time spent in the mouth during the first 5 min was $108 \pm 47.67$ (s.D.) sec].

We also compared feeding during the six tests of memory to feeding in the control animals. For this analysis, the six control groups were combined into one. One-way ANOVAs showed that there were significant differences in both the time to stop responding $[\mathrm{P}<0.0001, \mathrm{~F}(6,77)=12.30]$ and in the time that food was in the mouth during the first $5 \min [P=0.002, F(6,77)=3.95]$, between the six tests of memory and the combined control animals. Values during each of the six tests were then compared with the values observed in the control animals, using Dunnet's test (one tailed), which compares a number of different treatments to a single control (Edw ards 1972). The time to stop responding was significantly reduced during the 5-min $[\mathrm{P}<0.0001, \mathrm{t}(38)=4.96], 30-\mathrm{min}$ $[\mathrm{P}<0.0001, \mathrm{t}(42)=5.89], 1-\mathrm{hr}[\mathrm{P}=0.01, \mathrm{t}(45)=$ 2.29], and 24-hr $[P<0.0001, \mathrm{t}(39)=4.86]$ tests but not during the $4-h r[P=0.41, t(46)=0.22]$ or 
12-hr $[\mathrm{P}=0.44, \mathrm{t}(39)=0.45]$ tests. The time that food was in the mouth was significantly reduced during the $30-\min [\mathrm{P}=0.0001, \mathrm{t}(42)=3.94]$ and 24-hr $[\mathrm{P}=0.004, \mathrm{t}(39)=2.79]$ tests but not during the 5-min $[\mathrm{P}=0.46, \mathrm{t}(38)=0.01]$, 1 -hr $[\mathrm{P}=0.40$, $\mathrm{t}(45)=0.25], 4-\mathrm{hr}[\mathrm{P}=0.31, \mathrm{t}(46)=0.49]$, or $12-\mathrm{hr}$ $[\mathrm{P}=0.13, \mathrm{t}(39)=1.14]$ tests. These comparisons are consistent with the finding that separable short- and long-term memory processes are initiated by a single training session, with no memory observed during an intermediate period.

\section{ABBREVIATED TRAINING INDUCES ONLY LONG-TERM MEMORY}

In the experiment described above, animals w ere trained with inedible food until they stopped responding. However, previous studies (Schwarz et al. 1991; Schwarz and Susswein 1992) have show $n$ that even an abbreviated training session is sufficient to cause long-term memory $24 \mathrm{hr}$ after training. We examined whether an abbreviated training session can also give rise to short-term memory.

In this experiment, A. californica were trained as above, but the training was stopped at the end of $5 \mathrm{~min}$. Either 0.5 or $24 \mathrm{hr}$ later the animals were tested, using a blind procedure. The tests were continued until the animals stopped responding to the food. Following the abbreviated training there was a significant difference $[\mathrm{P}<0.001, \mathrm{t}(14)=$ 9.54; two-tailed t-test] in the time needed to stop responding to the food betw een animals that were tested $0.5 \mathrm{hr}$ and $24 \mathrm{hr}$ after training (Fig. 3A). The time to stop responding $0.5 \mathrm{hr}$ after training was similar to that in naive animals, whereas the time to stop responding $24 \mathrm{hr}$ after training was similar to that in the initial training $24 \mathrm{hr}$ previously until they stopped responding. This finding indicates that an abbreviated training is sufficient to cause long-term but not short-term memory.

Data on the time spent in the mouth were consistent with this conclusion (Fig. 3B). When animals w ere tested $0.5 \mathrm{hr}$ after training, there was no significant difference between the time spent in the mouth in the initial 5 min of training and during the first $5 \mathrm{~min}$ of the test $[\mathrm{P}=0.11, \mathrm{t}(5)=$ 1.93]. In contrast, there was a significant decrease in the time spent in the mouth during the first 5 min of the test $24 \mathrm{hr}$ after training, with respect to that seen during the 5-min training $[P=0.001$, $\mathrm{t}(9)=4.76$; two-tailed paired t-tests]).
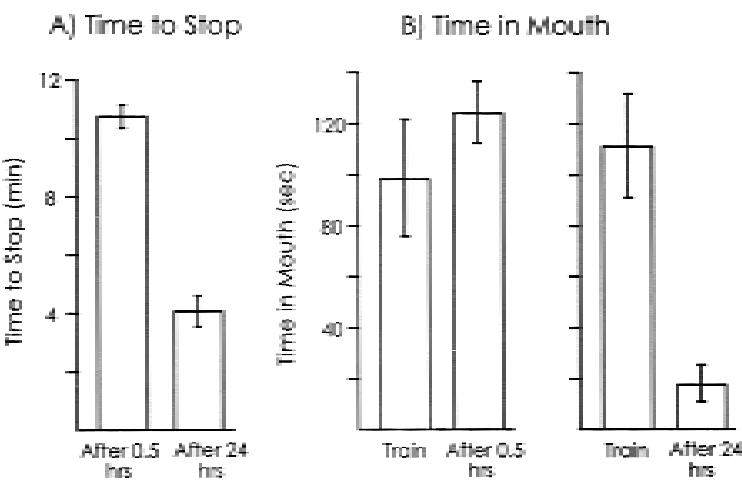

Figure 3: Effect of abbreviated training. The initial training was interrupted after $5 \mathrm{~min}$, and animals were tested either after $0.5 \mathrm{hr}(n=6)$ or after 24 hours $(n=10)$. The test was continued until animals stopped responding to the food. Means and S.E.S are shown. $(A)$ The time to stop responding in the test $0.5 \mathrm{hr}$ and $24 \mathrm{hr}$ after training. The time to stop responding after $0.5 \mathrm{hr}$ was similar to that in naive animals, whereas the time to stop responding after $24 \mathrm{hr}$ was similar to that in animals that had been trained with a full training session (see Fig. 1 ). (B) The time that food was in the mouth during the first $5 \mathrm{~min}$ of training and during the first $5 \mathrm{~min}$ of the two tests. There were no savings after $0.5 \mathrm{hr}$, but there were significant savings after $24 \mathrm{hr}$.

The finding that abbreviated training produces long-term memory identical to that seen after a full training session, but does not cause short-term memory, indicates that the expression of shortterm memory is not required for the subsequent expression of long-term memory. This finding also indicates that the earlier portion of a full training session is sufficient for causing long-term memory, whereas the later portion is needed to elicit shortterm memory.

\section{COOLING REDUCES LONG-TERM MEMORY}

In humans, as well as in many other animals (Squire 1987; Dudai 1989), post-training experiences can prevent the consolidation of a memory from short-term to long-term stores. In Caenorhabditis, Drosophila, and Limax, cooling of the whole animal has been used to block memory consolidation (Quinn and Dudai 1976; Yamada et al. 1992; Morrison and van der Kooy 1997). Cooling presumably blocks long-term memory by reducing the animal's metabolism and thereby reducing energy-dependent protein synthetic processes that are necessary components of memory consolidation (Davis and Squire, 1984). We examined the effects 
of cooling on training Aplysia that a food is inedible, as well as on the expression of short- and long-term memory.

Preliminary experiments examined the effects of cooling 15 animals for $10 \mathrm{~min}$ at $0^{\circ} \mathrm{C}$. Subsequent experiments examined the effects of cooling 30 animals for $15 \mathrm{~min}$ at $-20^{\circ} \mathrm{C}$. These experiments showed that animals recovered rapidly from cooling. After both procedures, during the first minute after the animals were restored to their cages after the cooling, the animals remained unresponsive at the bottom of the cage, with the foot unattached to the substrate. By 2-3 min after the cooling, they began to make weak movements of the tentacles and rhinophores. Animals became attached to the substrate and began to crawl slowly from 5 to 7 min after their return to their cages. By the end of 10 min, locomotion seemed completely normal. Animals that were provided with food also ate normally at this time. How ever, touching food to the rhinophores 15 min after cooling caused strong withdrawal responses, suggesting that withdrawal reflexes w ere somew hat sensitized. Nonetheless, it was possible to elicit feeding responses and to train animals by touching the rhinophores with the netted food very gently, to prevent withdrawal.

In preliminary experiments, A. californica were trained that a food is inedible, until they stopped responding to the food. They were then cooled $\left(10 \mathrm{~min}\right.$ at $\left.0^{\circ} \mathrm{C}\right)$ within $30 \mathrm{sec}$ of the termination of the training. Some animals $(n=4)$ were then tested after $30 \mathrm{~min}$, whereas other animals $(\mathrm{n}=6)$ were tested after $24 \mathrm{hr}$. Essentially normal learning and memory were observed in these animals (data not shown).

Because the effects of the cooling seemed to be very benign, we examined the effects caused by a more extreme procedure. In these experiments, A. californica were trained that a food is inedible, until they stopped responding to the food. They were then cooled $\left(15 \mathrm{~min}\right.$ at $\left.-20^{\circ} \mathrm{C}\right)$ within $30 \mathrm{sec}$ of the termination of the training. In one group of animals, memory was tested $0.5 \mathrm{hr}$ following the training (15 min after the end of the cooling), whereas in a second group, memory was tested 24 $\mathrm{hr}$ after the training. Along with the animals cooled after training and then tested after $0.5 \mathrm{hr}$ and $24 \mathrm{hr}$, control animals were examined that were cooled for $15 \mathrm{~min}$ before being trained, rather than immediately after the training. The cooling was for 15 min, which began 30 min before training, and ended 15 mins before the training. The experiments were performed using a blind procedure.

\section{COOLING BEFORE TRAINING DOES NOT AFFECT TRAINING}

We tested whether the cooling for 15 min before training affects the subsequent ability of the animals to learn (Fig. 4). During the initial training, there was no significant difference in the time to stop responding $[\mathrm{P}=0.23, \mathrm{t}(29)=1.22]$ or in the time that food was in the mouth during the first 5 min of training $[P=0.93, t(29)=0.09$; two-tailed t-tests] between animals that had been cooled 15 min before the training and those that were cooled subsequent to the training. Thus, the cooling did not affect the initial training. This was consistent with the observation that animals recovered remarkably quickly from the cooling.

COOLING BEFORE OR AFTER TRAINING DOES NOT AFFECT SHORT-TERM MEMORY

We examined whether cooling before or after training differentially affects short-term memory

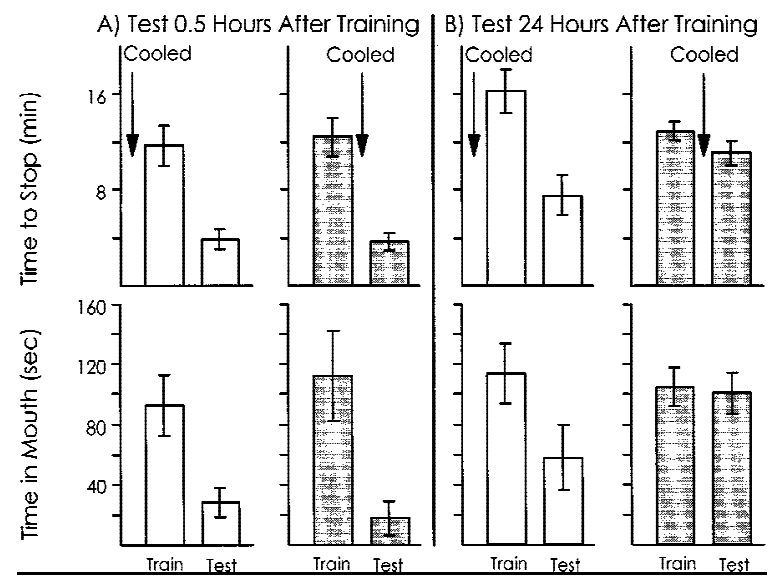

Figure 4: Effect of cold before and after training on learning and memory. Means and S.E.S are shown for both the time to stop responding to food (top) and for the time in the mouth during the first 5 min of a training or test session (bottom). ( $A$ ) In one group (open bars, $n=5$ ), animals were cooled and then trained until they stopped responding to food and then tested $0.5 \mathrm{hr}$ after the training. In a second group (shaded bars: $n=6$ ), animals were trained until they stopped responding to food and were then cooled and then tested $0.5 \mathrm{hr}$ after the training. (B) One group (open bars, $n=8$ ) was cooled, trained, and then tested after $24 \mathrm{hr}$. A second group (shaded bars, $n$ 11) was trained, then cooled, and then tested after $24 \mathrm{hr}$. Cooling before training did not affect either the ability to learn or short- or long-term memory. Cooling after training did not affect short-term memory but did attenuate long-term memory.

\section{$\begin{array}{llllllllllllllll}L & E & A & R & N & I & N & G & \underset{210}{\mathbf{X}} & M & E & M & O & R & Y\end{array}$}


(Fig. 4A). When animals were tested $0.5 \mathrm{hr}$ after training, there were no significant differences betw een animals that had been cooled before or after training in the time to stop responding to food $[P=0.43, t(10)=0.17]$ or in the time that food was in the mouth during the first 5 min of training $[\mathrm{P}=0.26, \mathrm{t}(10)=0.66$; one-tailed t-tests $]$. In previous experiments on animals that had not been cooled, $0.5 \mathrm{hr}$ after the original training the time to stop responding was reduced to $41.7 \pm 7.6 \%$ (S.E.M.) of the value seen in the initial training (see Fig. 2). In the present experiment, the time to stop responding to food was reduced to $33.9 \pm 5.7 \%$ (S.E.M.) of the initial value in animals that were cooled before training and to $29.6 \pm 6.7 \%$ (S.E.M.) of the initial value in animals that were cooled after training. There was no significant difference betw een these three values $[\mathrm{P}=0.48, \mathrm{~F}(2,17)=0.77$; one-way ANOVA]. In addition, in the previous experiment testing animals $0.5 \mathrm{hr}$ after training, the time in the mouth during the first 5 min of the test was reduced to $29.7 \pm 10.3 \%$ (S.E.M.) of the value during the initial training (see Fig. 2). In the present experiment, this value was reduced to $28.0 \pm 9.6 \%$ (S.E.M.) in animals that were cooled before training and to $17 \pm 11.4 \%$ (S.E.M.) in animals that were cooled after training. There was no significant difference between these three values $[\mathrm{P}=0.52, \mathrm{~F}(2,17)=0.68$; one-w ay ANOVA $]$. These data indicate that neither cooling before training nor cooling after training affects short-term memory measured $0.5 \mathrm{hr}$ after the training.

COOLING AFTER BUT NOT BEFORE TRAINING AFFECTS LONG-TERM MEMORY

We also examined whether cooling before or after training differentially affect long-term memory (Fig. 4B). In animals that were tested $24 \mathrm{hr}$ after the training, there $w$ as a significant difference between animals that had been cooled before or after training in the time to stop responding to food $[P=0.04, t(18)=1.92]$, as well as in the time that food $w$ as in the mouth during the first 5 min of training $[P=0.05, t(18)=1.78$; one-tailed t-tests]. The values measured in animals that were cooled before training were similar to those seen previously (see Figs. 1 and 2) $24 \mathrm{hr}$ after the initial training, whereas the values in animals cooled after training were elevated. During the second session in the previous experiment, the time to stop responding was reduced to $43.1 \pm 8.0 \%$ (S.E.M.) of the initial value (see Fig. 2). In animals that were cooled before training, the time to stop was reduced to $48.7 \pm 9.9 \%$ (S.E.M.) of the initial value, whereas in animals that were cooled after training, the time to stop was $85 \pm 5.18 \%$ (S.E.M.) of the initial value. The difference between these three values was significant $[P<0.001, F(2,22)=10.14]$. This $w$ as a result of significant differences between the animals that were cooled after training and the other two treatments, with no significant difference between uncooled animals and animals that were cooled before the training $\mathrm{P}<0.05$, StudentNew man-Keuls test). In addition, during the second session in the previous experiment (see Fig. 2 ), the time in the mouth during the first 5 min 24 $\mathrm{hr}$ after training was reduced to $51.8 \pm 20.5 \%$ (S.E.M.) of the value during the initial training. In the present experiments, the time in the mouth 24 hr after training was $49.3 \pm 19.4 \%$ (S.E.M.) of that in the first session in animals that were cooled before training. In contrast, in animals cooled after training, the time in the mouth was elvated to $101 \pm 11.0 \%$ (S.E.M.) of the initial value. The difference between these three values was significant $[P=0.04, F(2,22)=3.82]$, as a result of a significant difference between animals that were cooled after training and the uncooled animals, with no significant difference between uncooled animals and animals that were cooled before the training $(\mathrm{P}<0.05$, Student-New man-Keuls test). These data indicate that the cooling before training has no effect on long-term memory. In contrast, cooling after training strongly attenuates long-term memory.

An additional experiment was performed to replicate the finding that cooling immediately after training, but not before training, attenuates longterm memory. As in the previous experiment, animals were cooled either 15 min before being trained or immediately after the training. All animals w ere then tested $24 \mathrm{hr}$ later. This experiment confirmed that cooling after training attenuates long-term memory. The time to stop responding was significantly increased $24 \mathrm{hr}$ after the initial training $[\mathrm{P}<0.001, \mathrm{t}(8)=9.39]$ in animals that were cooled after training [14.5 \pm 2.2 (s.D.) min], with respect to the time to stop in animals that were cooled immediately before training [3.24 \pm 0.8 (S.D.) min]. Similarly, the time that food was in the mouth during the first 5 min of the test after $24 \mathrm{hr}$ was significantly increased $[\mathrm{P}=0.02$, $\mathrm{t}(8)=2.41$; one-tailed t-tests] in animals that had been cooled after training [110 \pm 83.9 (S.D.) sec],

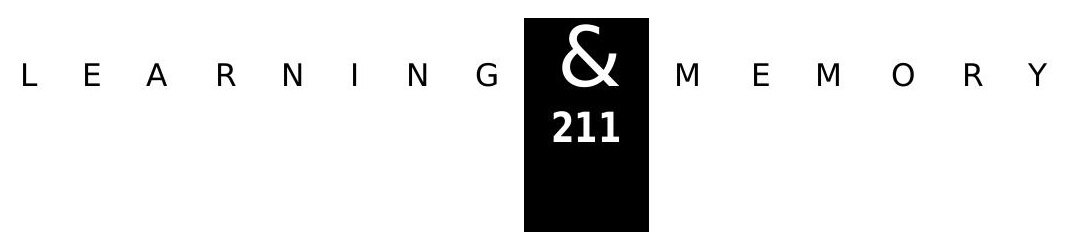


with respect to the value in animals that had been cooled before training [1.28 \pm 1.3 (S.D.) sec].

In two animals, the temperature adjacent to the head ganglia was measured immediately after animals were removed from being cooled to $-20^{\circ} \mathrm{C}$ for $15 \mathrm{~min}$. Temperatures were found to be 3.5$4^{\circ} \mathrm{C}$. This finding is consistent with the relatively benign effects caused by the cooling, because it is unlikely that the ganglia were damaged by freezing, and is also consistent with the possibility that cooling inhibits long-term memory by low ering the metabolism of the central ganglia.

It is possible that the effects of cooling on longterm memory could be attributed to the handling that animals received when they were removed from their cages and transferred to the cold, rather than to the cold itself. This possibility is consistent with a previous finding (Kupfermann and Weiss 1981) that handling animals modulates feeding behavior. How ever, in experiments in which animals were lifted and briefly removed from the water and then transferred to other chambers, animals show ed essentially normal memory measured after $24 \mathrm{hr}$ (Schwarz et al. 1998), indicating that benign handling similar to that occurring when animals were cooled would not by itself affect long-term memory.

\section{INTERMEDIATE-TERM MEMORY IS ATTAINED BY SPACED TRAINING}

The data above show that short-term memory is over within $1 \mathrm{hr}$ or less, and long-term memory becomes evident $12 \mathrm{hr}$ or more following training, with a period of 1-12 hr after training in which no memory is seen. This finding is somew hat surprising, because a previous study (Chiel and Susswein 1993) using a different training procedure did show memory during this period. In this study animals were exposed ad libitum to inedible food, rather than training them by continuously stimulating the lips with this food. Animals periodically encountered the food, tried to eat it, and then rejected it. How ever, whereas in the present training procedure the experimenter continued stimulating the lips, in the ad libitum procedure the animals crawled aw ay from the food, thereby removing it from their lips and preventing the food from initiating a second round of biting and failed swallowing. Thus, training bouts were spaced over a considerable period, with the spacing governed by the animal's likelihood of encountering the food. We reasoned that a training procedure designed to be more similar to that seen in ad libitum training could give rise to memory in the period before long-term memory becomes evident.

In this experiment, A. californica were trained with three 5-min exposures to inedible netted food. The three training sessions were separated from one another by $0.5 \mathrm{hr}$. Four hours after the final session, using a blind procedure, memory was tested by retraining the animals until they stopped responding to the food. Two controls were examined. In both, animals received only a single training session. One control group was trained until the animals stopped responding to the food, whereas the other control group received only a single 5-min training session. Both control groups were also examined $4 \mathrm{hr}$ after training (Fig. 5).

There were significant differences in the time needed to stop responding to the inedible food in

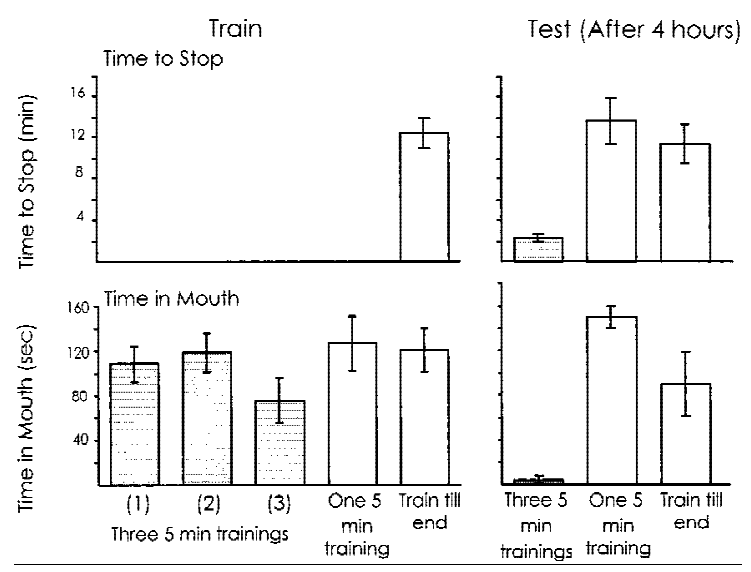

Figure 5: Distributed training elicits intermediate-term memory. The experimental animals (shaded bars) received three abbreviated (interrupted at the end of 5 min) training sessions separated by half-hour intervals $(n=8)$. Memory was tested $4 \mathrm{hr}$ after the end of the training. Two control groups (open bars) were tested along with the experimental group. O ne group $(n=6)$ received a single abbreviated training session (treatment identical to that in Fig. 3), and the other group $(n=4)$ received a single training session until they stopped responding to food (treatment identical to that in Fig. 1). The data are shown separately for the training and testing. The time to stop during training is shown only for the single control group in which the training was not abbreviated. O nly the distributed training caused significant memory after $4 \mathrm{hr}$. Note that there is no significant difference $[P=0.10, t(7)=1.86$, two-tailed paired $t$-test $]$ in the time spent in the mouth between the first and second training sessions, confirming the lack of memory $0.5 \mathrm{hr}$ after an abbreviated training session (see Fig. 3). 
the three groups tested $4 \mathrm{hr}$ after the initial training $[\mathrm{P}<0.001, \mathrm{~F}(2,15)=19.84$; one-w ay ANOVA]. For the two control groups that had received a single training, the times to stop were similar to those in naive animals, whereas the time to stop in the animals that had received multiple training sessions was significantly shorter $[\mathrm{P}<0.001, \mathrm{t}(16)=6.02$; one-tailed t-test comparing animals receiving three 5-min training sessions with combined data from both control groups]. These data indicate that the repeated brief training sessions lead to significant memory after $4 \mathrm{hr}$, whereas a single training session does not.

Data on the time spent in the mouth also show ed memory $4 \mathrm{hr}$ following the multiple training sessions. There were significant differences in the time spent in the mouth between the three groups tested $4 \mathrm{hr}$ after training $[\mathrm{P}<0.001$, $\mathrm{F}(2,15)=17.87$; one-w ay ANOVA]. The time spent in the mouth during the first 5 min of the test in the two control groups was similar to that seen in naive animals, whereas this measure was significantly reduced in the animals that had received three 5min training sessions $[\mathrm{P}<0.001, \mathrm{t}(16)=4.95$; onetailed t-test comparing animals receiving three 5min training sessions with combined data from both control groups].

These data indicate that an intermediate-term memory can affect the response to inedible food during the period in which neither short-term nor long-term memory is present. However, the generation of the intermediate-term memory is dependent on spacing of a number of training sessions, whereas a single training session is sufficient to give rise to both short-term and long-term memory.

\section{A VERY SHORT-TERM MEMORY IS EVIDENT DURING TRAINING}

Previous studies have show $n$ that the responsiveness to food gradually declines while animals are being trained (Susswein et al. 1986). The responsiveness to food during the second 5 min of training is already less than that seen during the first $5 \mathrm{~min}$. How ever, the data above indicate that when a half-hour separates tw 0 5-min training sessions, there is no decrease in the response (see Figs. 3 and 5). These findings suggest that the first 5 min of a learning trial initiates a very short-term memory process, which influences the subsequent $5 \mathrm{~min}$, but which is essentially over if the training is interrupted and the animals are tested $0.5 \mathrm{hr}$ later.
To quantify the decline of the very short-term memory that occurs during training, we compared the time spent in the mouth after three training procedures (Fig. 6). In one, A. californica were trained for $5 \mathrm{~min}$, and then they were tested for an additional $5 \mathrm{~min}$ immediately after the first $5 \mathrm{~min}$, without an interruption. In the second group, the animals were trained for $5 \mathrm{~min}$, allow ed a rest of 15 $\mathrm{min}$, and then tested again for $5 \mathrm{~min}$. In the third group, the animals were permitted a 30-min rest between the two 5 -min training procedures.

There was a significant difference in the time spent in the mouth between the first and the second 5-min period when the two periods followed one another immediately $[\mathrm{P}<0.001, \mathrm{t}(8)=7.11$; one-tailed paired t-test]. When a 15-min rest separated the two 5-min exposures to food, there was no significant difference in the time spent in the mouth $[\mathrm{P}=0.30, \mathrm{t}(4)=0.56$; one-tailed paired $\mathrm{t}$ test]. These data show that the very short-term memory declines within 15 min.

\section{Discussion}

In many organisms, learning initiates a number of memory processes that are distinguished on the basis of differences in their time of expression, as well as in sensitivity to various physical or pharmacological procedures (Squire 1987; Dudai 1989). Our data show that a training procedure in which Aplysia learn that a food is inedible leads to four

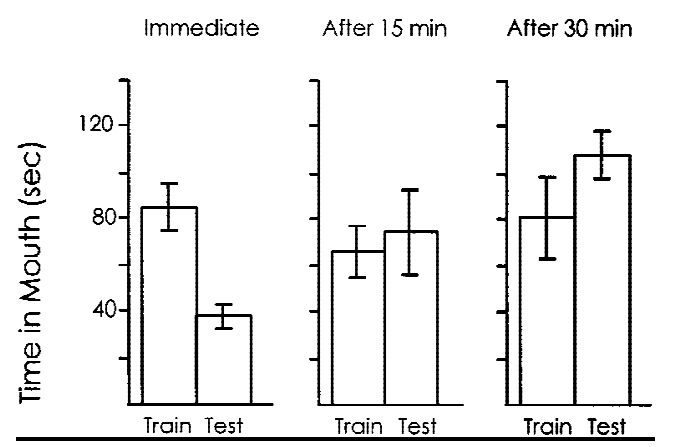

Figure 6: Very short-term memory decays within 15 min. Animals were trained for $5 \mathrm{~min}$ and were then tested for another $5 \mathrm{~min}$. The second $5 \mathrm{~min}$ either followed immediately the first $5 \mathrm{~min}(n=19)$ or occurred after $15(n=5)$ or $30 \mathrm{~min}(n=11)$. M eans and S.E.S are shown. There was a significant difference between the training and testing only in animals in which the test was immediately after the training, indicating that $15 \mathrm{~min}$ is enough time to cause a decay of the very short-term memory. 
separable memory processes. The memory processes that were identified are similar in their time course to those previously found in sensory-to-motor neuron synapses in Aplysia that are facilitated by pulses of serotonin (Emptage and Crew 1993; Ghirardi et al. 1995; Mauelshagen et al. 1996). However, the training procedures needed to elicit the various memory processes are unusual and somew hat unexpected. A brief training is sufficient to cause long-term memory, a longer training is required for short-term memory, and spaced training is needed for intermediate-term memory. These findings also represent the first time that distinct memory phases, particularly a separable intermediate-term memory, have been identified in behaving Aplysia, by the use of different training procedures.

\section{RELATIONSHIP BETWEEN LONG-AND SHORT-TERM MEMORY}

Long-term memory has been explored in both vertebrates and invertebrates. In habituation and sensitization of Aplysia withdrawal reflexes (Carew et al. 1972; Pinsker et al. 1973) and in odor conditioning in Drosophila (Tully et al. 1994), short-term memory occurs after one training session, and long-term memory requires multiple, spaced training sessions. In Aplysia, short-term and long-term sensitization are mimicked respectively by a single application of serotonin or by spaced applications of serotonin onto sensory neurons initiating the reflex (Montarolo et al. 1986; Rayport and Schacher 1986; Schacher et al. 1990; Emptage and Carew 1993). Serotonin activates a secondmessenger cascade in which the intracellular concentration of CAMP is increased (Ocorr et al. 1986). CAMP has also been implicated as an essential second messenger in both long-term and short-term memory in Drosophila (Dudai 1989) and in some forms of mammalian LTP and long-term memory (Huang et al. 1994; Abel et al. 1997; Guzow ski and McGaugh 1997). The increased CAMP activates protein kinase A. In Aplysia sensory neurons, a single pulse of serotonin causes an increase in the concentration of the catalytic subunit of the kinase in neurites (Bacskai et al. 1993) and a consequent regulation of local channel proteins (Byrne and Kandel 1996). Multiple pulses of serotonin cause a larger increase in the concentration of the catalytic subunit and a subsequent translocation to the nucleus (Bacskai et al. 1993). The catalytic subunit phosphorylates CREB, thereby facilitating its bind- ing with DNA, initiating transcription of mRNAs that are appropriate for cellular changes underlying long-term memory. Thus, short-term and longterm memory are caused by the same transmitter and second messenger, but the threshold concentrations of CAMP and of the catalytic subunit of protein kinase $A$ are higher for the long-term effect (Ghirardi et al. 1995). Nonetheless, long- and shortterm memory are independent and parallel processes in Aplysia (Emptage and Carew 1993; Mauelshagen et al. 1996) and Hermissenda (Crow and Forrester 1993). In Drosophila, mutants affecting early stages of memory after olfactory classical conditioning also affect later stages, indicating that later stages of memory are dependent on the earlier stages (Tully et al. 1994). How ever, after conditioned courtship, long-term memory can be observed in the absence of a preceding short-term memory (Kane et al. 1997), indicating that longand short-term memory represent independent processes.

For learning that a food is inedible in Aplysia, we have found that short-term and long-term memory are also separate, parallel phenomena. Thus, an abbreviated training elicits only the longterm memory, without the prior expression of short-term memory (Fig. 3). Unlike the previous studies, which demonstrated the independence of short- and long-term memories in reduced preparations, we have shown this separation in intact, behaving animals. How ever, our data are inconsistent with the model that long-term memory is signaled by a higher concentration of the same second messengers as those signaling short-term memory, because long-term memory is elicited by a briefer training session than is short-term memory. Our data can be explained if the threshold for long-term memory is lower than that for short-term memory. Additional possible explanations are that short-and long-term memory are generated and stored in different neurons or are signaled by different second-messenger cascades. The latter suggestion is consistent with a previous finding that short- and long-term memory of learned changes in the visual system of Hermissenda are both initiated by serotonin but are mediated by different second-messenger systems (Crow and Forrester 1993). A variety of second-messenger systems are also activated as a result of sensitization of Aplysia withdrawal reflexes, and these differentially affect various cellular aspects of short- and long-term memory (Byrne and Kandel, 1996). It is also possible that short-and long-term memory that

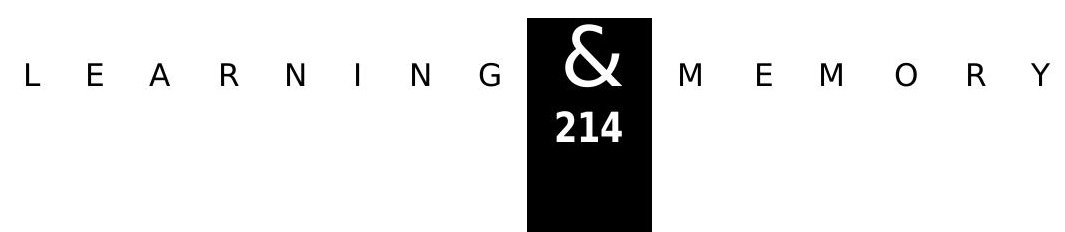


a food is inedible represent fundamentally different processes. Previous work has shown that longterm memory arises as a result of an associative conditioning process, as show $n$ by specificity to a particular food (Susswein et al. 1986). How ever, we have not examined the processes underlying short-term memory, and it is possible that a nonassociative process is responsible, as is the case for short-term memory (but not long-term memory) caused by pairing serotonin with light in Hermissenda (Crow and Forrester 1991).

Unlike learning of withdraw al reflexes in Aplysia or olfactory learning in Drosophila, in which spaced training is needed to achieve long-term memory, in our learning paradigm even a single brief training session leads to long-term memory. It has been suggested that the requirement for spaced training to induce long-term memory is adaptive, because long-term memory of an event that occurs only once in an animal's lifetime may be unnecessary or even counterproductive ( $Y$ in et al. 1995). How ever, previous studies have shown that even well-trained Aplysia respond to food at a low rate (Chiel and Susswein 1993). Thus, if the animal mistakenly learns that a food is inedible after a single brief training, it can easily unlearn its mistake. A single pairing betw een light and serotonin also causes long-term changes in Hermissenda photoreceptors (Crow and Forrester 1991).

The requirement for spaced training in the formation of long-term memory has been explained by the presence of both activator and repressor isoforms of CREB in neurons (Bartsch et al. 1995; Yin et al. 1995). Spaced training causes an increase in the relative concentration of an activator isoform. Experimental treatments decreasing the concentration of a repressor isoform can lead to longterm memory after a single training trial (Bartsch et al. 1995; Y in et al. 1995). It is possible that repressor isoforms are naturally present in low concentrations in the neurons responsible for learning that food is inedible.

An unusual feature of learning that a food is inedible is that a training procedure eliciting both short- and long-term memory also leads to a long gap with no expression of memory (Fig. 2). Similar gaps between short- and long-term memory are also seen in the learning of avoidance responses in rats (Kamin 1957) and in olfactory conditioning of the honeybee (Hammer and Menzel 1995). However, in both of these systems, the gap betw een the end of short-term memory and the initiation of long-term memory is no more than a few minutes, whereas in our system, at least $12 \mathrm{hr}$ separate the two processes. A 15-hr gap between short- and long-term memory that is remarkably similar to ours is also seen in the facilitation by serotonin of Aplysia synapses that function in tail withdrawal (Mauelshagen et al. 1996). In this system, shortterm facilitation decays within 15-30 min following one to four pulses of serotonin, whereas longterm facilitation begins to be observed $15 \mathrm{hr}$ following the application of five pulses of serotonin. Thus, the delay in the time of onset for long-term memory is similar in synaptic facilitation and in learning that a food is inedible, suggesting that similar processes may underlie the delay of both. How ever, the decay time for short-term facilitation of the sensory-to-motor synapse corresponds more closely to the decay of what we have called very short-term memory, rather than to our short-term memory, which is still robust 30 min after training. These findings are consistent with previous work showing that short-term memory is not itself a single process. A number of second-messenger cascades participate in the synaptic modulation that underlies short-term memory (Byrne and Kandel 1996).

A hallmark of long-term memory is that a process of memory consolidation is needed before the memory is expressed. After animals are trained but before the memory is consolidated, it can be interrupted by inhibition of protein synthesis or by various traumas such as electroconvulsive shock, heat, or cold (Squire 1987; Dudai 1989; Yamada et al. 1992; Beck and Rankin 1995; DeZazzo and Tully 1995; Morrison and van der Kooy 1997). Such treatments do not affect the expression of shortterm memory. These data are consistent with our finding that cooling animals 15 min before training them that a food is inedible does not affect the ability of animals to learn and also has no effect on either short-term or long-term memory (Fig. 4). In contrast, cooling animals immediately after training strongly reduces long-term memory, without affecting short-term memory (Fig. 4). Previous data (M. Schwarz and A.J. Susswein, unpubl.; Schwarz et al. 1998) have also shown that isolating an animal for an hour after it has been trained blocks the expression of long-term memory. Treatments that affect memory consolidation are generally effective during a brief critical period following training. We have not yet explored the critical period in which cooling affects memory consolidation. We have also not explored the underlying mechanism by which cooling affects memory. How ever, in Aply-

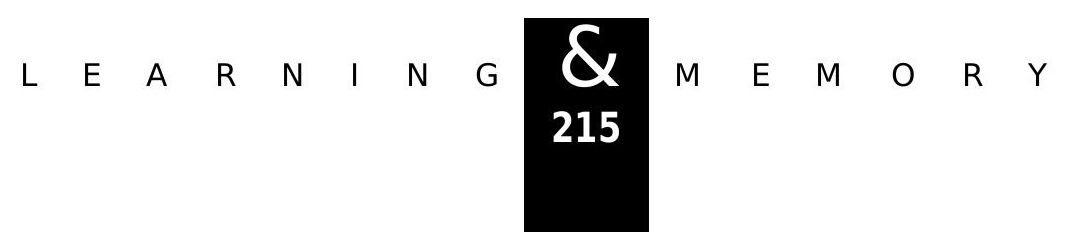


sia (Montarolo et al. 1986) and in many other organisms (Davis and Squire 1984), long-term memory is dependent on protein synthesis, which is an energy-dependent process. Cooling reduces the metabolic rate and thereby partially or completely blocks processes that require energy. Although this mechanism seems to be a reasonable explanation of how cooling blocks long-term memory, we cannot eliminate the possibility that cooling acts because it is a traumatic experience. In humans and in other animals, emotionally charged or stressful events can either enhance or depress learning and memory (Squire 1987). However, the relatively benign effects caused by cooling argue against this possibility.

\section{INTERMEDIATE-TERM MEMORY}

Distributed training that a food is inedible leads to memory that is seen after $4 \mathrm{hr}$. This finding suggests that a separable intermediate-term memory is initiated by distributed training. A separable intermediate-term memory is also seen after learning in rats, chicks, and Drosophila (Tully et al. 1994; DeZazzo and Tully 1995), as well as in Aplysia sensory neurons that are exposed to multiple pulses of serotonin (Ghirardi et al. 1995; Mauelshagen et al. 1996). In Aplysia, distributed pulses of serotonin elicit memory for $1-3 \mathrm{hr}$ after the training. This has been attributed to two processes: One is an amplification of the short-term memory and is unaffected by inhibitors of both transcription and translation, whereas the other is apparently a unique, independent process that requires translation but not transcription (Ghirardi et al. 1995). In learning that a food is inedible, we have no data regarding whether the distributed training causes a more sustained and robust short-term memory that is seen even after $4 \mathrm{hr}$ or whether it causes an independent, intermediate-term process. Another possibility is that additional training trials facilitate the formation of long-term memory, so that its onset is earlier. Such a process occurs in odor learning in honeybees (Menzel and Sugawa 1986). We have not yet explored whether memory after $4 \mathrm{hr}$ is associative or whether it can be affected by cooling or by other forms of trauma.

\section{VERY SHORT-TERM MEMORY}

We have found that the first 5 min of training also elicit a very short-term decrease in responsive- ness. This process is over within $15 \mathrm{~min}$. The decrease is unlikely to be attributable to sensory adaptation or habituation caused by the exposure to food per se, because a previous study has shown that sustained exposure to food causes a decrease in responsiveness only after $\sim 1 \mathrm{hr}$ of stimulation (Schwarz et al. 1988). The time course of the very short-term memory is similar to that of the initial component of food-induced arousal (Susswein et al. 1978; Kupfermann et al. 1991), except that it is of opposite sign: Food-induced arousal facilitates feeding, whereas the very short-term memory observed in this study inhibits it. Food arousal is mediated by the sustained activity of specialized modulatory neurons, as well as by the effects of neuromodulatory cotransmitters (Kupfermann et al. 1991). Both food-induced arousal and the very short-term memory shown above are reminiscent of working memory in higher animals (GoldmanRakic 1995) and may be functional analogs to it. We have not yet explored whether the very shortterm memory is an associative process or whether it arises from the rejection responses initiated by the inedible food. We have also not yet explored the relationship between the expression of this process in the latter portion of a training session and the short-term memory, which is dependent on the processes that occur in the latter portion of a training session.

\section{AD LIBITUM TRAINING}

The training procedures required for different memory stages that a food is inedible are highly unusual and seem to be counterintuitive. As noted above, in other learning paradigms a single brief training elicits short-term memory, longer, more intense (or spaced) training elicits intermediateterm memory, and spaced training is required to elicit long-term memory. In contrast, in our learning paradigm, a brief training session caused longterm memory, a longer training session was needed for short-term memory, and spaced training was needed to elicit intermediate-term memory. However, in nature these counterintuitive aspects of training are unlikely to be expressed. A previous study (Chiel and Susswein 1993) simulated training in conditions similar to those that are likely to occur in nature, when animals have free access to an inedible food. In that study, the animals sporadically encountered the food and attempted to eat it. The animal's pattern

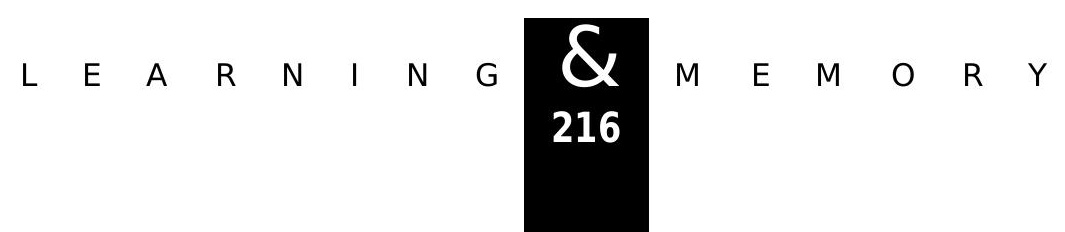


of training itself was spaced and, in all likelihood, initiated all of the memory processes described above. Over a period of $2 \mathrm{hr}$, the responsiveness to inedible food gradually decreased and reached a steady-state, low-level responsiveness. During this state, memory was show $n$ by changes in the animal's behavior: The animal encountered the inedible food less frequently and responded to it less vigorously when it was encountered. Memory could also be displayed when the food was removed for a period and then restored. Animals initially responded vigorously, but there was a decrease in the time needed to reach the steady-state, low-level responsiveness. Thus, as in many other learning paradigms, in the absence of experimental intervention, memory had the appearance of a seamless, continuous process, and the different components w ere effectively hidden. An important outcome of the natural training pattern is that it is of little consequence which part of a training session causes short-, intermediate-, or long-term memory, because the animal is always trained in a manner that elicits all of the memory processes. Thus, evolution can make use of unconventional, seemingly counterintuitive training mechanisms to elicit memory, if they do not interfere with attaining the particular task at hand. More conventional schemes of memory stages seem appropriate only when the possibility arises of animals being selectively exposed to training procedures that can initiate only some but not all of the memory stages.

\section{Acknowledgments}

We thank Drs. Irving Kupfermann, Thomas Teyke, and Aron Weller for comments on the manuscript. This work was supported by U.S.-Israel Binational Science Foundation grant 93-224 and Israel Science Foundation grant 413/97.

The publication costs of this article were defrayed in part by payment of page charges. This article must therefore be hereby marked "advertisement" in accordance with 18 USC section 1734 solely to indicate this fact.

\section{References}

Abel, T., P.V. N guyen, M. Barad, T.A.S. Deuel, E.R. Kandel, and R. Bourtchouladze. 1997. Genetic demonstration of a role for PKA in the late phase of LTP and in hippocampus-based long-term memory. Cell 88: 615-626.

Bacskai, B.J., B. Hochner, M. Mahaut-Smith, S.R. Adams, B.-K. Kaang, E.R. Kandel, and R.Y. Tsien. 1993. Spatially resolved dynamics of CAMP and protein kinase $A$ subunits in Aplysia sensory neurons. Science 260: 223-226.

Bartsch, D., M. Ghirardi, P.A. Skehel, K.A. Karl, S.P. Herder,
M. Chen, C.H. Bailey, and E.R. Kandel. 1995. Aplysia CREB2 represses long-term facilitation: Relief of repression converts transient facilitation into long-term functional and structural change. Cell 83: 979-992.

Beck, C.D.O. and C.H. Rankin. 1995. Heat shock disrupts long-term memory consolidation in Caenorhabditis elegans. Learn. \& Mem. 2: 161-177.

Bourtchuladze, R., B. Frenguelli, J. Blendy, D. Cioffi, G. Schutz, and A.J. Silva. 1994. Deficient long-term memory in mice with a targeted mutation of the CAM P-responsive element-binding protein. Cell 79: 59-68.

Byrne, J.H. 1987. Cellular analysis of associative learning. Physiol. Rev. 67: 329-439.

Byrne, J.H. and E.R. Kandel. 1996. Presynaptic facilitation revisited: State and time dependence. J. Neurosci.

16: 425-435.

Carew, T.J. and C.L. Sahley. 1986. Invertebrate learning and memory: From behavior to molecules. Annu. Rev. Neurosci. 9: 435-487.

Carew, T.J., H.M. Pinsker, and E.R. Kandel. 1972. Long-term habituation of a defensive withdrawal reflex in Aplysia. Science 175: 451-454.

Chiel, H.J. and A.J. Susswein. 1993. Learning that food is inedible in freely-behaving Aplysia californica. Behav. Neurosci. 107: 327-338.

Crow, T. and J. Forrester. 1991. Light paired with serotonin in vivo produces both short- and long-term enhancement of generator potentials of identified B-photoreceptors in Hermissenda. J. Neurosci. 11: 608-617.

--- . 1993. Down-regulation of protein kinase $C$ and kinase inhibitors dissociate short-and long-term enhancement produced by one-trial conditioning of Hermissenda. J. Neurophysiol. 69: 636-641.

Dash, P.K., B. Hochner, and E.R. Kandel. 1990. Injection of the CAM P-responsive element into the nucleus of Aplysia sensory neurons blocks long-term facilitation. Nature 345: 718-721.

Davis, H.P. and L.R. Squire.1984. Protein synthesis and memory: A review. Psychol. Bull. 96: 518-559.

DeZazzo, J. and T. Tully. 1995. Dissection of memory formation: From behavioral pharmacology to molecular genetics. Trends Neurosci. 18: 212-218.

Dudai, Y. 1989. The neurobiology of memory: Concepts, findings, trends. Oxford U niversity Press, New York, NY.

Edwards, A.L. 1972. Experimental design in psychological research, 4th ed. Holt, Rinehard, and Winston, New York, NY.

Emptage, N.J. and T.J. Carew. 1993. Long-term synaptic

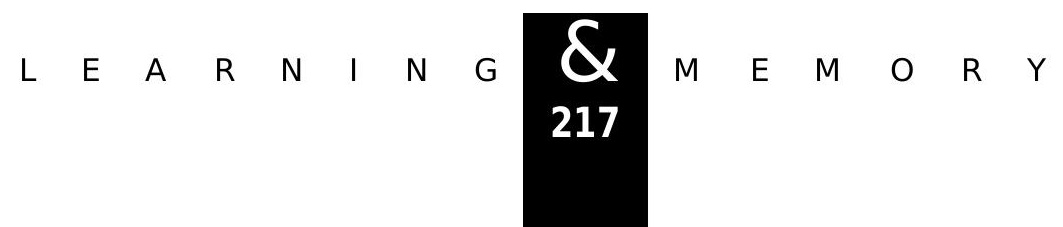




\section{Botzer et al.}

facilitation in the absence of short-term facilitation in Aplysia neurons. Science 262: 253-256.

Ghirardi, M., P.B. Montarolo, and E.R. Kandel. 1995. A novel intermediate stage in the transition between short- and long-term facilitation in the sensory to motor neuron synapse of Aplysia. Neuron 14: 413-420.

Goldman-Rakic, P.S. 1995. Cellular basis of working memory. Neuron 14: 477-485.

Guzowski, J.F. and J.L. McGaugh. 1997. Antisense oligodeoxynucleotide-mediated disruption of hippocampal CAM $P$ response element binding protein levels impairs consolidation of memory for water maze training. Proc. Natl. Acad. Sci. 94: 2693-2698.

Hammer, M. and R. Menzel. 1995. Learning and memory in the honeybee. J. Neurosci. 15: 1617-1630.

Huang, Y.-Y., X.-C. Li, and E.R. Kandel. 1994. cAMP contributes to mossy fiber LTP by initiating both a covalently mediated early phase and macromolecular synthesis-dependent late phase. Cell 79: 69-79.

Hurwitz, I. and A.J. Susswein. 1996. B64, a newly-identified central pattern generator element producing a phase switch from protraction to retraction in buccal motor programs of Aplysia californica. J. Neurophysiol. 75: 1327-1344.

Hurwit, I., D. Neustadter, D. Morton, H.J. Chiel, and A.J. Susswein. 1996. Activity patterns of the B31/B32 pattern initiators innervating the 12 muscle of the buccal mass during normal feeding movements in Aplysia californica. J. Neurophysiol. 75: 1309-1326.

Hurwitz, I., I. Kupfermann, and A.J. Susswein. 1997. Different roles of neurons B63 and B34 that are active during the protraction phase of buccal motor programs in Aplysia californica. J. Neurophysiol. 78: 1305-1319.

Kabotyanski, E.A, D.A. Baxter, and J.H. Byrne. 1998. Identification and characterization of catecholaminergic neuron $\mathrm{B} 65$, which initiates and modifies patterned activity in the buccal ganglia of Aplysia. J. Neurophysiol. 79: 605-621.

Kamin, L.J. 1957. The retention of an incompletely learned avoidance response. J. Comp. Physiol. Psychol. 50: 457-460.

Kandel, E.R. and J.H. Schwartz. 1982. Molecular biology of learning: Modulation of transmitter release. Science 218: 433-443.

Kane, N.C., A. Robichon, J.A. Dickinson, and R.J. Greenspan. 1997. Learning without performance in PKC-deficient Drosophila. Neuron 18: 307-314.

Kupfermann, I. 1968. A circadian locomotor rhythm in Aplysia californica. Physiol. Behav. 3: 179-181.

- - . 1974. Feeding behavior in Aplysia: A simple system for the study of motivation. Behav. Biol. 10: 1-26.
Kupfermann, I. and K.R. Weiss. 1981. Tail pinch and handling facilitate feeding behavior in Aplysia. Behav. Neural Biol. 32: 126-132.

Kupfermann, I., T. Teyke, S.C. Rosen, and K.R. Weiss. 1991. Studies of behavioral state in Aplysia. Biol. Bull. 180: 262-268.

Mauelshagen, J., G.P. Parker, and T.J. Carew. 1996. Dynamics of induction and expression of long-term synaptic facilitation in Aplysia. J. Neurosci. 16: 7099-7108.

Menzel, R. and M. Sugawa. 1986. Time course of short-term memory depends on associative events. Naturwissenschaften 73: $564-565$

Montarolo, P.G., P. Goelet, V.F. Castellucci, J. Morgan, E.R. Kandel, and S. Schacher. 1986. A critical period of macromolecular synthesis in long-term heterosynaptic facilitation in Aplysia. Science 234: 1249-1254.

Morrison, G.E. and D. van der Kooy. 1997. Cold shock before associative conditioning blocks memory retrieval, but cold shock after conditioning blocks memory retention in Caenorhabditis elegans. Behav. Neurosci. 111: 564-578.

Morton, D.W. and H.J. Chiel. 1993. In vivo buccal nerve activity that distinguishes ingestion from rejection can be used to predict behavioral transitions in Aplysia. J. Comp. Physiol. A 172: 17-32.

Nargeot, R., D.A. Baxter, and J.H. Byrne. 1997. Contingent-dependent enhancement of rhythmic motor patterns: An in vitro analog of operant conditioning. J. Neurosci. 17: 8093-8105.

O corr, K.A., M. Tabata, and J.H. Byrne. 1986. Stimuli that produce sensitization lead to elevation of cyclic AMP levels in tail sensory neurons of Aplysia. Brain Res. 371: 190-192.

Perrins, R. and K.R. W eiss. 1996. A cerebral central pattern generator in Aplysia and its connections with buccal feeding circuitry. J. Neurosci. 16: 7030-7045.

Pinsker, H.M., W.A. Hening, T.J. Carew, and E.R. Kandel. 1973. Long-term sensitization of a defensive withdrawal reflex in Aplysia. Science 182: 1039-1042.

Plummer, M.R. and M.D. Kirk. 1990. Premotor neuron-B51 and neuron-B52 in the buccal ganglia of Aplysia californica-Synaptic connections, effects on ongoing motor rhythms and peptide modulation. J. Neurophysiol. 63: $539-558$

Q uinn, W.G. and Y. Dudai. 1976. Memory phases in Drosophila. Nature 262: 576-577.

Rayport, S.G. and S. Schacher. 1986. Synaptic plasticity in vitro: Cell culture of identified Aplysia neurons mediating short-term habituation and sensitization. J. Neurosci. 6: $759-763$.

Rosen, S.C., T. Teyke, M.W. Miller, K.R. W eiss, and I.

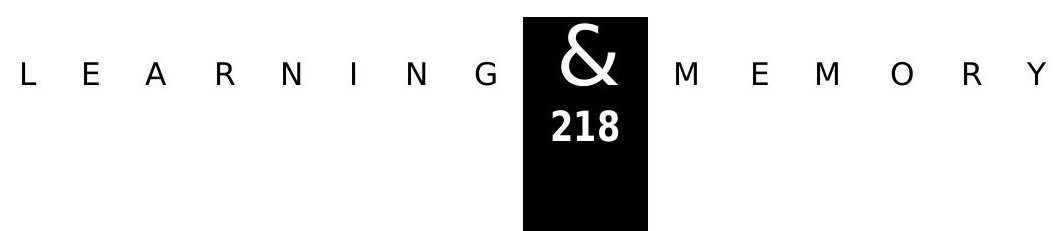




\section{MEMORY AND INEDIBLE FOOD IN APLYSIA}

Kupfermann. 1991. Identification and characterization of cerebral-to-buccal interneurons implicated in the control of motor programs associated with feeding in Aplysia. J. Neurosci. 11: 3630-3655.

Schacher, S., P.G. Montarolo, and E.R. Kandel. 1990. Selective short- and long-term effects of serotonin, small cardioactive peptide, and tetanic stimulation on sensorimotor synapses in culture. J. Neurosci. 10: 3268-3294.

Schwarz M. and A.J. Susswein. 1986. Identification of the neural pathway for reinforcement of feeding when Aplysia learn that food is inedible. J. Neurosci. 6: 1528-1536.

- - - 1992. Presence of conspecifics facilitates learning that food is inedible in Aplysia fasciata. Behav. Neurosci. 106: $250-261$.

Schwarz, M., S. Markovich, and A.J. Susswein. 1988. Parametric features of inhibition of feeding in Aplysia by associative learning, satiation and sustained lip stimulation. Behav. Neurosci. 102: 124-133.

Schwarz, M., E. Feldman, and A.J. Susswein. 1991. Variables affecting long-term memory of learning that a food is inedible in Aplysia. Behav. Neurosci. 105: 193-201.

Schwarz, M., S. Blumberg, and A.J. Susswein. 1998. Social isolation blocks the expression of memory following training that a food is inedible in Aplysia fasciata. Behav. Neurosci. (in press).

Squire, L.R. 1987. Memory and brain. Oxford University Press, New York, NY.

Susswein, A.J. and J.H. Byrne. 1988. Identification and characterization of neurons initiating patterned neural activity in the buccal ganglia of Aplysia. J. Neurosci. 8: 2049-2061.

Susswein, A.J., K.R. W eiss, and I. Kupfermann. 1978. The effects of food arousal on the latency of biting in Aplysia. J. Comp. Physiol. 123: 31-41.

Susswein, A.J., M. Schwarz, and E. Feldman. 1986. Learned changes of feeding behavior in Aplysia in response to edible and inedible foods. J. Neurosci. 6: 1513-1527.

Teyke, T., K.R. W eiss, and I. Kupfermann. 1990. An identified neuron (CPR) evokes neuronal responses reflecting food arousal in Aplysia. Science 247: 85-87.

Teyke, T., S.R. Rosen, K.R. W eiss, and I. Kupfermann. 1993. Dopaminergic neuron B20 generates rhythmic neuronal activity in the feeding motor circuitry of Aplysia. Brain Res. 630: 226-237.

Tully, T., T. Preat, S.C. Boynton, and M. Del Vecchio. 1994. Genetic dissection of consolidated memory in Drosophila.

Cell 79: 35-47.

Weiss, K.R., J.L. Cohen, and I. Kupfermann. 1978.

Modulatory control of buccal musculature by a serotonergic neuron (metacerebral cell) in Aplysia. J. Neurophysiol. 41: 181-203.

Yamada, A., T. Sekiguchi, H. Suzuki, and A. Mizukami. 1992. Behavioral analysis of internal memory states using cooling-induced retrograde amnesia in Limax flavus. J. Neurosci. 12: 729-735.

Yin, J.C.P., M. Del Veccio, H. Zhou, and T. Tully. 1995. CREB as a memory modulator: Induced expression of a $d C R E B 2$ activator isoform enhances long-term memory in Drosophila. Cell 81: 107-115.

Ziv, I., C. Lustig, M. Ben-Zion, and A.J. Susswein. 1991. Daily variation of multiple behaviors in Aplysia fasciata: Integration of feeding, reproduction and locomotion. Behav. Neural Biol. 55: 86-107.

Received October 1, 1997; accepted in revised form March 30, 1998.

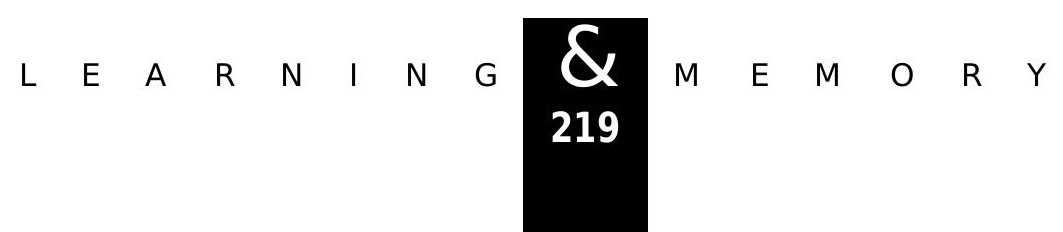




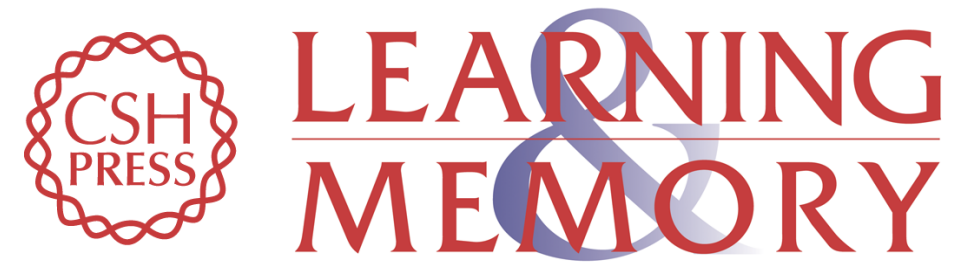

\section{Multiple Memory Processes Following Training That a Food Is Inedible in Aplysia}

Dina Botzer, Silvia Markovich and Abraham J. Susswein

Learn. Mem. 1998, 5:

Access the most recent version at doi:10.1101//m.5.3.204

References This article cites 58 articles, 20 of which can be accessed free at:

http://learnmem.cshlp.org/content/5/3/204.full.htmI\#ref-list-1

License

Email Alerting Receive free email alerts when new articles cite this article - sign up in the box at the Service top right corner of the article or click here. 